\title{
RECUPERAÇÃO DE ROLOS DE LAMINAÇÃO *
}

Enilson dos Anjos Rodrigues ${ }^{1}$

\section{Resumo}

Com a crescente demanda do mercado siderúrgico por aumento de produtividade e melhoria dos produtos laminados, tem surgido a necessidade de melhoria dos revestimentos aplicados nos rolos puxadores "Pinch roll", rolos abraçadores "wrapper rolls", rolos alimentadores "Feed roll" rolos de mesa (table roll) dentre outros rolos que compõem uma linha laminação. Hoje uns dos grandes desafios encarados pelas indústrias de produção de consumíveis de solda e empresas prestadoras de serviços de recuperação de rolos, estão diretamente ligados no desenvolvimento de novas ligas que permitam um melhor desempenho e desenvolvimento de novos procedimentos que garantam maior qualidade do revestimento aplicado.

Palavras-chave: Revestimento de rolos; Laminação de tiras à quente; rolos puxadores, rolos abraçadores.

\section{RECOVERY OF HOT STRIP MILL ROLLS}

\begin{abstract}
Due the demand of market to increase de production, improvements of product quality and decrease operations cost, comes up the need to increase life and quality of the rolls used in hot strip mill, among them stand out Pinch Rolls, Wrapper rolls, Feed rolls, that represent an important position to rolling process. Therefore, is clear the need of improve de roll cladding, the machinery and procedures applied to manufacture and repair the them. The improve made on roll cladding reduce down time and increase production.
\end{abstract}

Keywords: Roll cladding, hot rolling mill, Pinch rolls: Wrapper rolls.

1 Engenharia Mecânica, Engenheiro, Especialista em recuperação de rolos, Coordenação técnica, SMS Group, Vespasiano, Minas Gerais, Brasil. 


\section{INTRODUCTION}

Com a crescente demanda do mercado siderúrgico por aumento de produtividade e melhoria dos produtos laminados, tem surgido a necessidade de melhoria dos revestimentos aplicados nos rolos puxadores "Pinch roll", rolos abraçadores "wrapper rolls", rolos alimentadores "Feed roll" rolos de mesa (table roll) dentre outros rolos que compõem uma linha laminação. Hoje uns dos grandes desafios encarados pelas indústrias de produção de consumíveis de solda e empresas prestadoras de serviços de recuperação de rolos, estão diretamente ligados no desenvolvimento de novas ligas que permitam um melhor desempenho e desenvolvimento de novos procedimentos que garantam maior qualidade do revestimento aplicado.

\section{MATERIAL AND METHODS}

Este documento foi desenvolvido considerando as fabricações e reparos realizados recentemente e também os estudos de desenvolvimentos realizados para melhoria dos processos e materiais pela SMS Group.

\section{RESULTS AND DISCUSSION}

Durante o processo de fabricação de chapas de aço, são utilizados vários equipamentos e dentre estes estão os laminadores de tiras à quente. Este equipamento tem a função de reduzir a espessura das chapas que são produzidas através do processo de lingotamento contínuo. Normalmente as chapas provenientes do lingotamento tem a espessura entre 200 a $250 \mathrm{~mm}$ e ao final do processo atinge espessuras entre 2 a $20 \mathrm{~mm}$. Este trabalho terá seu foco voltado para alguns rolos, que digamos são auxiliares ao processo de laminação, pois não estão diretamente empregados no processo de redução da espessura das tiras, mas apresentação funções vitais para o processo, e se estes não apresentarem um alto nível de tecnologia, principalmente nos revestimentos que são aplicados, podem acarretar em má qualidade dos produtos laminados. Para isso, é importante entender os mecanismos de desgaste dos rolos que estão envolvidos no processo. A figura 1 apresenta um layout dos rolos que são passiveis de recuperação. 
ultrassom e composição química da região a ser soldada são imprescindíveis em todos os processos de recuperação, pois ele que permitirá conhecer o estado inicial dos rolos e assim definir a melhor forma para a recuperação.

Rolos que apresentarem trincas, poros concentrados em grande quantidade ou outros tipos de defeitos que possa comprometer a recuperação devem ser usinados até a completa remoção das descontinuidades e teste de LP e ultrassom devem ser realizado para garantir que os desfeitos foram completamente eliminados. Após a completa remoção dos defeitos, a região deve ser recomposta com material compatível com o metal de base. A Figura 2 apresenta o processo de pré-usinagem e LP que foram realizados na mesa de um Pinch roll superior e inferior.

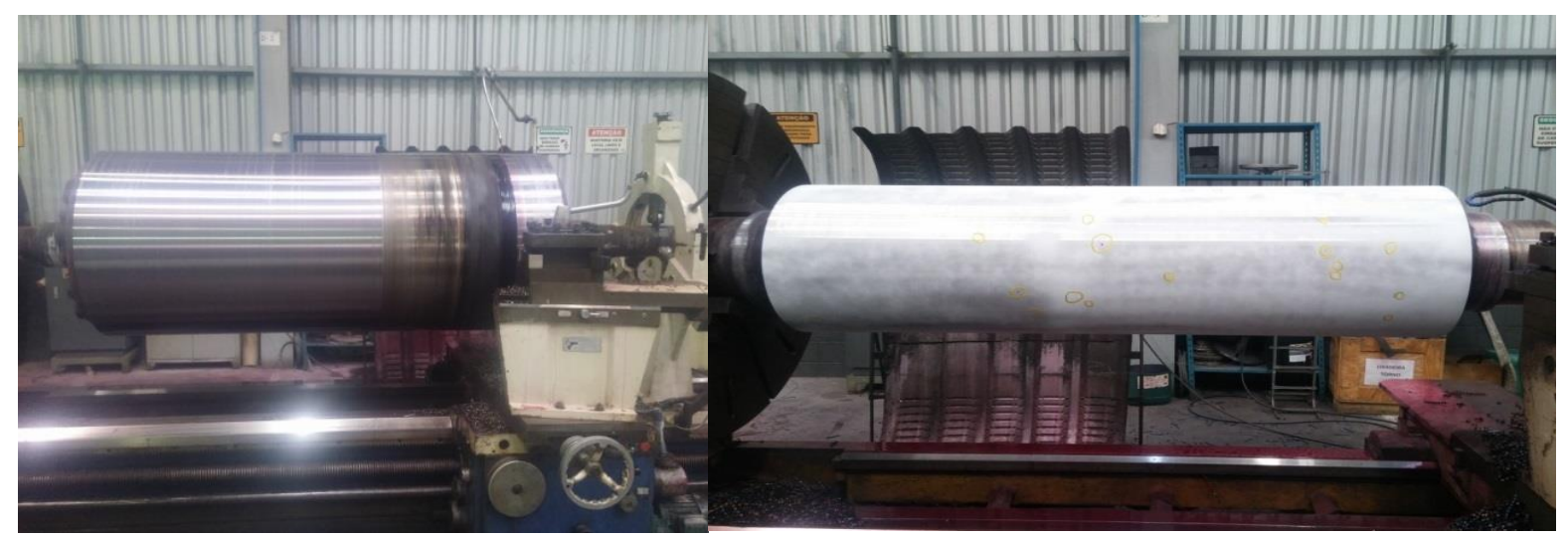

Figura 2: Pré-usinagem e LP em Pinch rolls

\subsection{Aplicação do revestimento}

A aplicação da camada de amanteigamento e do revestimento duro comumente é realizado através do processo de soldagem arco submerso ou arco aberto, pois esses processos de solda possuem alta taxa de deposição o que é fundamental para este tipo de recuperação, devido às dimensões dos rolos e o volume de metal de solda depositado. Para os dois processos de soldagem mencionados anteriormente, pode se utilizar o movimento de oscilação da tocha que propicia 0 aumento do cordão de solda, podendo este chegar até $60 \mathrm{~mm}$ de largura, e assim ter um aumente da ordem de $50 \%$ na taxa de deposição.

Outro fator positivo ao se trabalhar com o movimento de oscilação da tocha está na redução da quantidade de sobreposição de passe. $O$ motivo pelo qual essa redução é benéfica está relacionado à fragilização que ocorre em alguns materiais quando eles são refundidos durante a sobreposição. Pois o fenômeno da sensitização e corrosão inter-critalinas são reduzidos. Um importante avanço no sentido da redução da sensitização foi à adição de nitrogênio na fabricação dos arames.

A figura 2 apresenta o processo de recuperação de um Pinch roll Inferior, no qual foi utilizado o processo de soldagem arco submerso. 

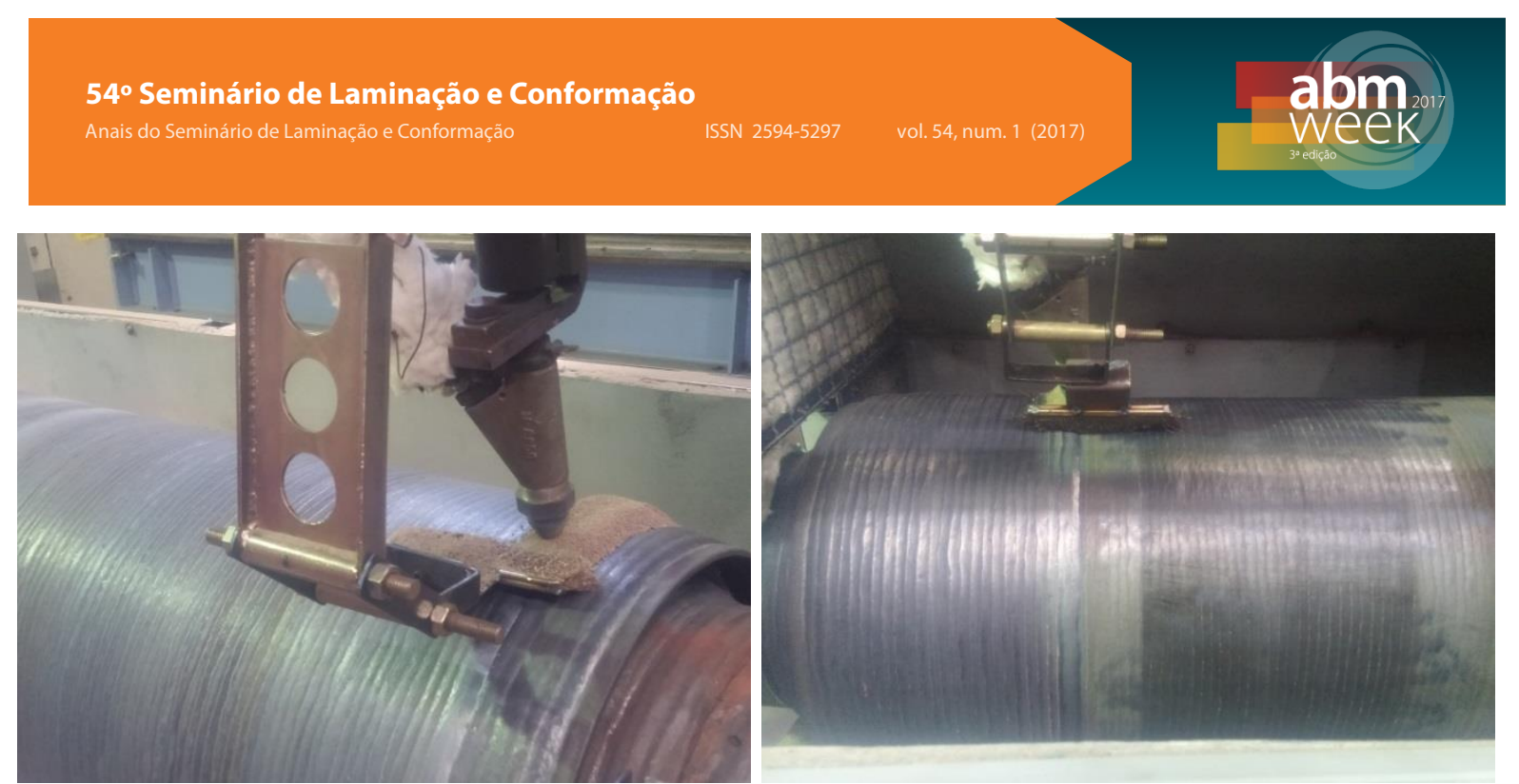

Figura 2: Recuperação de Pinch roll inferior.

\subsection{Controle de temperatura dos rolos}

Um dos pontos primordiais para uma recuperação bem sucedida dos rolos é o controle preciso da temperatura, pois os materiais que são utilizados para revestir os rolos possuem alto teor de elementos de ligas e em alguns casos alto teor de carbono também, o que exigi temperatura de pré-aquecimento e interpasse bem elevadas. Entretanto devido a grande dificuldade de manter a temperatura dentro do range correto, vários defeitos podem surgir. Dentre eles destacam-se as trincas que são provenientes da grande concentração de microestruturas martensíticas causadas pela queda na temperatura do rolo e variação da dureza superficial dos rolos o que pode comprometer a vida útil em trabalho. Para solucionar o problema da variação da temperatura, a máquina utilizada para aplicação do revestimento deve conter alguns dispositivos que permitam controlar a temperatura. Dentre eles, pode-se citar um sistema de pré-aquecimento com queimadores acionados individualmente e um sistema de contenção do calor que evite que esse se perca para o ambiente.

A figura 4 mostra o funcionamento dos queimadores e um sistema de enclausuramento .

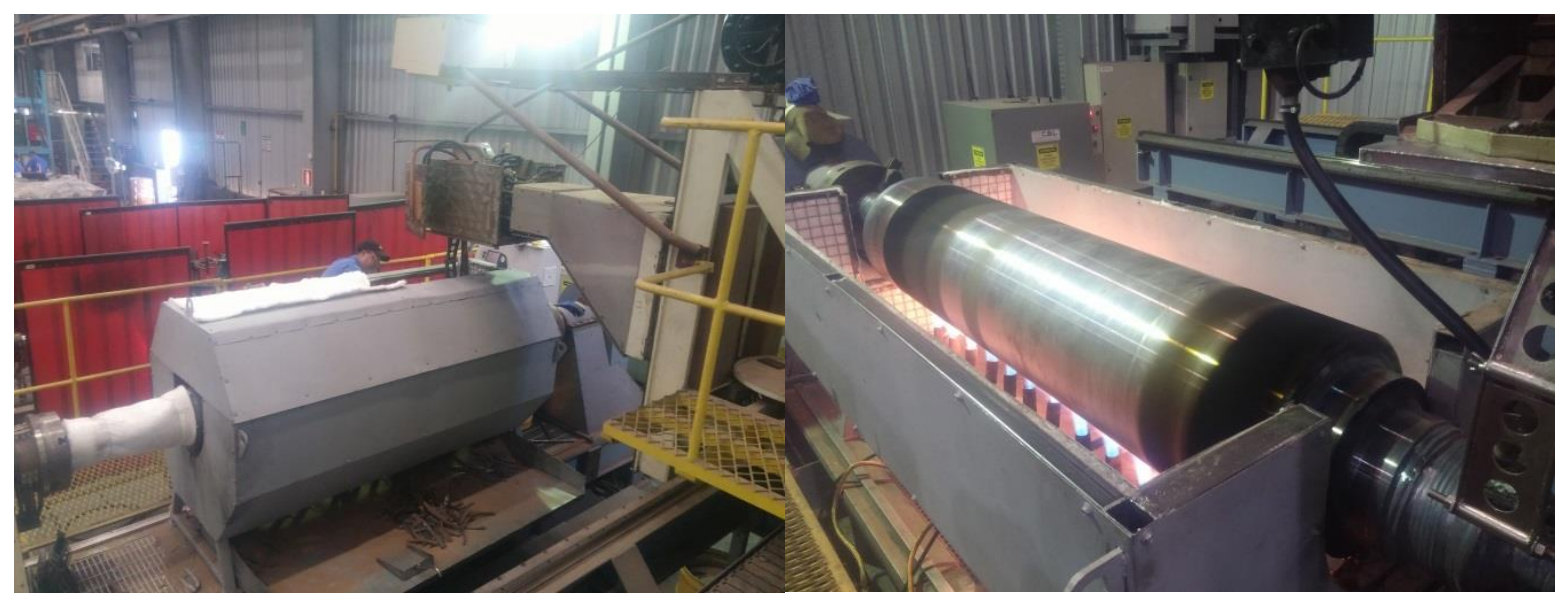

Figura 4: sistema de manutenção da temperatura de rolos. 


\subsection{Inspeção final}

Após o processo de recuperação e usinagem final o qual deve respeitar todas as dimensões de projeto e tolerâncias, as peças devem ser inspecionadas para garantir a eficácias da recuperação realizada. Para tal devem-se realizar inspeções dimensionais, $100 \%$ LP e ultrassom e teste de dureza, está ultima tem papel fundamental na vida útil da peça recuperada. Só após a aprovação dos rolos nesses quesitos ele pode ser liberado para ser enviado para o cliente.

\section{CONCLUSION}

Para realização de uma recuperação que seja satisfatória tanto do ponto de vista financeiro e quanto da qualidade do trabalho realizado, vários pontos devem ser observados durante o processo de recuperação. Talvez o mais importante deles seja a definição do procedimento de recuperação, no qual estarão presentes todas as diretrizes a serem seguidas durante o reparo, como o material a ser utilizado, a temperatura de pré-aquecimento e interpasse, os testes de inspeção a ser realizado, a camada de material a ser aplicada e o processo de soldas que será utilizado.

Com base nessas informações o programador da fabrica juntamente com os supervisores de áreas poderão programar todos os parâmetros inerentes ao processo.

\section{Acknowledgments}

A SMS Group por todos os estudos desenvolvidos ao longo de vários anos prestando serviço de recuperação de rolos tanto no Brasil quanto em outros países. 